\title{
APLICAÇÕES DE MISTURAS SOLO-“GRITS” EM ESTRADAS FLORESTAIS: RESISTÊNCIA MECÂNICA VIA CBR ${ }^{1}$
}

\author{
Reginaldo Sérgio Pereira ${ }^{2}$, Carlos Cardoso Machado ${ }^{3}$ e Carlos Alexandre Braz de Carvalho ${ }^{4}$
}

\begin{abstract}
RESUMO - Analisaram-se as potencialidades de emprego do resíduo sólido industrial "grits", oriundo da indústria de celulose, como agente estabilizante de dois solos da Zona da Mata Norte de Minas Gerais, Brasil, para fins de emprego em estradas florestais. Os solos estudados englobaram um residual maduro, de textura argilo-arenosiltosa, e um residual jovem, de textura areno-silto-argilosa. Para tanto, prepararam-se misturas envolvendo solos e o resíduo nos quantitativos de $4,8,12,16,20,24$ e $28 \%$ em relação às massas de solo seco. Fezse uso do ensaio CBR para avaliar as características de resistência e expansão das misturas. A avaliação dos resultados do estudo permite concluir que o resíduo "grits" apresentou potencial significativo como estabilizante dos solos, observando-se que: (i) a adição de "grits" aos solos foi responsável por ganhos nas suas resistências mecânicas, obtendo-se melhores resultados com o solo de textura areno-silto-argilosa; (ii) com relação à expansão medida no ensaio CBR, observaram-se pequenos acréscimos para o solo de textura argilo-areno-siltosa e decréscimos para o solo de textura areno-silto-argilosa, com aumentos no teor de "grits"; e (iii) as misturas solo-"grits" não responderam bem ao aumento da energia de compactação, quanto aos parâmetros CBR e expansão ${ }_{\mathrm{CBR}}$.
\end{abstract}

Palavras-chave: Solos, estabilização, resíduo industrial "grits” e estradas florestais.

\section{APPLICATION OF SOIL-GRITS MIXTURES IN FOREST ROADS: MECHANICAL STRENGTH VIA CBR TEST}

\begin{abstract}
This paper is directed to forest road engineering applications, and address the potentialities of using an industrial solid waste from the cellulose industry, named grits, in the stabilization process of two soils from Zona da Mata Norte of Minas Gerais States, Brazil. Soil types tested comprised a mature residual silty-sandy-clay and a young residual clayey-silty-sand. Soil-grits mixtures were prepared at 4, 8, 12, 16, 20, 24 and $28 \%$ stabilizer contents referred to soil dry masses. Mechanical strength and swelling parameters were determined by CBR (California Bearing Ratio) tests. The laboratory testing program data supported that addition of grits to soils led to: (i) significant mechanical strength gains that could be better associated with the clayey-silty-sandy soil; (ii) increases and decreases in swelling with increases in grits contents referred to the silty-sandy-clayey and the clayey-silty-sandy soils respectively, and (iii) increase in compaction effort did not lead to better mechanical responses of the mixtures regarding CBR and swelling ${ }_{C B R}$.
\end{abstract}

Keywords: Soils, stabilization, industrial waste grits and forest roads.

\footnotetext{
${ }^{1}$ Recebido em 22.11.2005 e aceito para publicação em 05.04.2006.

${ }^{2}$ Departamento de Engenharia Florestal da Universidade de Brasília, Brasília-DF. E-mail: <reginaldosp1@ yahoo.com.br>.

${ }_{3}^{3}$ Departamento de Engenharia Florestal da UFV, Viçosa-MG, Brasil. E-mail: <machado@ufv.br>.

${ }^{4}$ Departamento de Engenharia Civil da UFV, Viçosa-MG, Brasil. E-mail: <cabraz@ufv.br>.
} 


\section{INTRODUÇÃO}

Em estudos de estabilização química de solos para fins rodoviários, é comum desenvolver-se na dosagem um programa de ensaios de laboratório direcionado ao conhecimento das características de engenharia das misturas, com base nas normas técnicas padronizadas pela Associação Brasileira de Normas Técnicas (ABNT) ou pelo Departamento Nacional de Infra-Estrutura de Transportes (DNIT), antigo Departamento Nacional de Estradas de Rodagem (DNER). A resistência mecânica dos solos e misturas pode ser avaliada pelo índice de suporte Califórnia (ISC ou CBR), em que, além do valor da capacidade de suporte de amostras deformadas, obtém-se, também, o valor da expansão que, segundo Nogami e Villibor (1995), tem sido um parâmetro de grande importância em obras viárias.

O ensaio CBR, desenvolvido inicialmente pelo Departamento de Rodovias do Estado da Califórnia, EUA, foi adotado pelo Corpo de Engenheiros dos Estados Unidos, que, após introduzir modificações, divulgouo amplamente durante a Segunda Guerra Mundial (NOGAMI e VILLIBOR, 1995). No Brasil, os resultados desse ensaio são adotados quase que com exclusividade para o dimensionamento de pavimentos flexíveis, determinando-se a capacidade de suporte do subleito e das camadas do pavimento rodoviário. Exemplos nesse sentido são os métodos de dimensionamentos de pavimentos flexíveis do DNIT, antigo DNER, na versão mais atual do seu Manual de Pavimentação (DNIT, 1996).

Partindo do pressuposto de que se pode fazer uma escolha adequada das técnicas de estabilização química de solos para fins rodoviários, que numa definição de Lima et al. (1993) referem-se: “[...] à incorporação de uma pequena quantidade de aditivo na massa do solo, conferindo-lhe propriedades pre-determinadas;" diversos estabilizantes podem ser encontrados no mercado, podendo-se referir a produtos tradicionais, como cal, cimento e betume, passando por outros produtos comerciais, como Dynacal e RBI Grade 81, e finalizando com material alternativo, como subprodutos ou resíduos industriais.

Sherwood (1961) relatou experiências bem-sucedidas com o uso de resíduos industriais na estabilização química de solos de estradas, referindo às cinzas volantes e ao cloreto de cálcio. Esse autor destacou a distância de transporte da fábrica ao local de aplicação e quantidade de resíduo produzida como possíveis condicionantes no processo.
Na UFV, os Departamentos de Engenharia Civil e Engenharia Florestal têm acumulado experiência significativa nessa área, podendo-se destacar: (i) pesquisas desenvolvidas com o vinhoto, gerado na indústria açucareira e estudado por Ferraz (1994); (ii) licor-negro kraft, produzido na indústria de celulose e analisado por Vieira (1994); (iii) alcatrão de madeira de eucalipto, gerado no processo de carbonização da madeira e pesquisado por Fernandes (2000); e (iv) escórias de aciaria e de alto-forno, subprodutos da produção do aço e estudadas, respectivamente, por Baltazar (2001) e Sant' ana (2003). Uma visão geral das pesquisas desenvolvidas na UFV sobre o emprego de resíduos industriais em estradas foi apresentada por Lima et al., (2003), no $6^{\circ}$ Simpósio Brasileiro sobre Colheita e Transporte Florestal.

Dando prosseguimento a essa linha de pesquisa, surge um novo material, gerado na produção de celulose, denominado "grits", que possui em sua composição parcela significativa de óxido de cálcio que não reagiu durante o processo de recuperação da soda cáustica e que apresenta, portanto, potencial para a estabilização química de solos. O seu emprego como estabilizante de estradas florestais se fundamenta, também, nos seguintes fatos: (i) o resíduo é gerado em quantidade suficiente para ser usado nas estradas florestais; (ii) os locais de produção e aplicação do produto estão a distâncias de transporte economicamente viáveis; e (iii) o produto é classificado, segundo a Norma Técnica ABNT 10.004 (1987), como resíduo da classe II, ou seja, não inerte.

Assim, este trabalho é direcionado à análise da potencialidade do resíduo industrial "grits" como estabilizante químico para solos de estradas florestais. Procedeu-se à avaliação da resistência mecânica de amostras de solo com e sem adição do resíduo "grits", com o intuito de gerar dados laboratoriais como parte integrante de uma das etapas de uma série de estudos sobre a viabilidade de resíduos industriais em estradas. Como objetivos específicos abordados neste artigo, citam-se: (i) avaliação, via resultados dos ensaios CBR, da resistência e expansão de amostras de solo e misturas solo-"grits"; (ii) análise da influência de variações no teor de umidade de misturas solo-"grits" nas suas resistências mecânicas; e (iii) avaliação da influência da energia de compactação na resistência mecânica das misturas solo-"grits". 


\section{MATERIAL E MÉTODOS}

\subsection{Amostras de solo e de resíduo}

Neste estudo, trabalhou-se com amostras de dois solos residuais da Zona da Mata Norte de Minas Gerais, coletadas no Município de Viçosa, sendo um de comportamento laterítico e outro de comportamento saprolítico, segundo o sistema de classificação adotado na metodologia MCT (NOGAMI e VILLIBOR, 1995).

A primeira amostra, de comportamento geotécnico laterítico e classificação A-7-5 (20), segundo o sistema adotado pelo Transportation Research Board dos Estados Unidos da América e também pelo DNIT, apresenta textura argilo-areno-siltosa e foi coletada em um talude de corte da rodovia que une as cidades de Viçosa e Paula Cândido, nas proximidades da Estação de Tratamento de Água de Viçosa, sendo essa amostra denominada solo 1. A segunda amostra, de comportamento geotécnico saprolítico e classificação TRB A-2-4 (0), foi coletada em um talude de corte na Vila Secundino, localizada no Campus da UFV, sendo denominada solo 2 .

A escolha desses solos se deveu aos volumes significativos de suas ocorrências na Zona da Mata mineira e, especialmente, ao fato de representarem material muito diferenciado no sistema de classificação adotado pelo TRB, englobando aqueles de textura fina (solo 1) e granular (solo 2). As amostras coletadas no campo foram acondicionadas em embalagens plásticas e destinadas ao Laboratório de Engenharia Civil (LEC) da UFV para destorroamento, secagem ao ar e armazenamento em tambores para posterior utilização.

O resíduo "grits", que foi cedido pela Empresa de Celulose Nipo-Brasileira (CENIBRA), é um material sólido, de coloração acinzentada, que apresenta em sua constituição química o óxido de cálcio, ou seja, cal obtida na reação de caustificação do licor-verde, processo esse que recupera a soda cáustica para retorno ao cozimento da celulose. A amostra foi coletada em um aterro sanitário da empresa, transportado para o Laboratório de Engenharia Civil da UFV e estocado em tambores para utilização futura.

\subsection{Teores de "grits" utilizados e período de cura das misturas}

Os teores de "grits" empregados nas misturas foram: $0,4,8,12,16,20$ e $24 \%$, valores esses calculados sobre a massa de solo seco. Em razão das respostas obtidas no programa de ensaios, posteriormente acrescentouse à matriz de ensaios o traço de $28 \%$ de "grits". Ressaltase que as misturas solo-"grits" foram realizadas manualmente, com a adição de resíduo ao solo e homogeneização da massa. Posteriormente, adicionouse água às misturas em quantitativos predeterminados, procedendo-se à nova homogeneização.

Presentemente, não se trabalhou com períodos de cura úmida das misturas solo-"grits" compactadas, executando-se o ensaio CBR imediatamente depois de completado o período de imersão, em água, por 96 horas dos corpos-de-prova.

\subsection{Ensaios geotécnicos e respectivas normatizações técnicas}

Numa primeira etapa, com exceção da mistura das amostras de solos com $28 \%$ de "grits", fez-se uso do ensaio $\mathrm{CBR}_{5 \text { pontos }}$ para a determinação dos parâmetros ótimos de compactação (teor ótimo de umidade - $\mathrm{W}_{\text {ót }}$ e peso específico seco máximo - $\gamma_{\text {dmáx }}$ ) e da resistência mecânica e expansão das misturas (CBR e expansão ${ }_{\mathrm{CBR}}$ ), cuja compactação dos corpos-de-prova é normatizada pelo método de ensaio DNIT (1994) - ME 129. Nessa etapa, trabalhou-se com a energia de compactação do ensaio Proctor intermediário.

Para avaliar o efeito da energia de compactação na resistência mecânica das misturas, procedeu-se à compactação de corpos-de-prova destas, segundo o método de ensaio DNIT (1994) - ME 216, obtendose os parâmetros ótimos de compactação na energia do ensaio Proctor modificado. Em seguida, procedeuse à execução do ensaio $\mathrm{CBR}_{1 \text { ponto }}$, determinando os valores CBR e expansão ${ }_{\mathrm{CBR}}$ apenas no teor ótimo de umidade. Toda essa sequiência foi, também, adotada nas misturas preparadas com $28 \%$ de "grits".

\section{RESULTADOS E DISCUSSÃO}

\subsection{Parâmetros ótimos de compactação}

Apresentam-se, na Figura 1, as curvas de compactação, CBR e expansão ${ }_{\mathrm{CBR}}$, obtidas nos ensaios $\mathrm{CBR}_{5 \text { pontos }}$ realizados na energia do ensaio de compactação Proctor intermediário, mostrando-se, à esquerda, os resultados de ensaios do solo $1 \mathrm{e}$, à direita, do solo 2, ambos sem adição de "grits". $\mathrm{Na}$ energia de compactação anteriormente citada, os parâmetros ótimos

R. Árvore, Viçosa-MG, v.30, n.4, p.619-627, 2006 
da curva de compactação encontrados foram os seguintes: solo $1, \mathrm{~W}_{\text {ót }}$ de $28,87 \%$ e $\gamma_{\text {dmáx }}$ de $14,58 \mathrm{kN} / \mathrm{m}^{3}$; solo $2, \mathrm{~W}_{\text {ót }}$ de $11,38 \%$ e $\gamma_{\text {dmáx }} 18,33 \mathrm{kN} / \mathrm{m}^{3}$. Ainda na Figura 1 , trabalhando com os valores de $\mathrm{W}_{\text {ót }}$ nas curvas dos parâmetros CBR e expansão ${ }_{\mathrm{CBR}}$ versus teor de umidade, obtêm-se, respectivamente, os valores de 14 e $0,40 \%$ para o solo 1 e 20 e $1,3 \%$ do solo 2 .

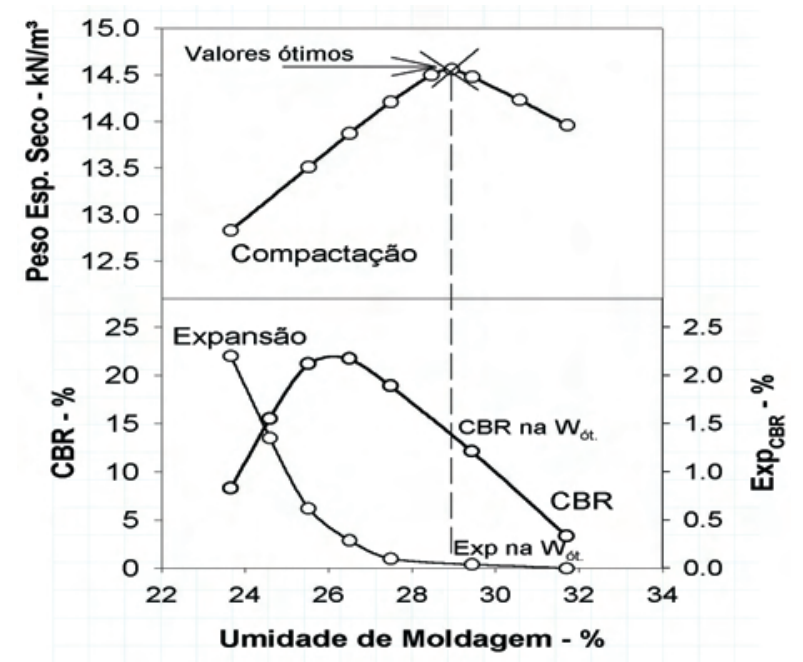

a) Solo 1

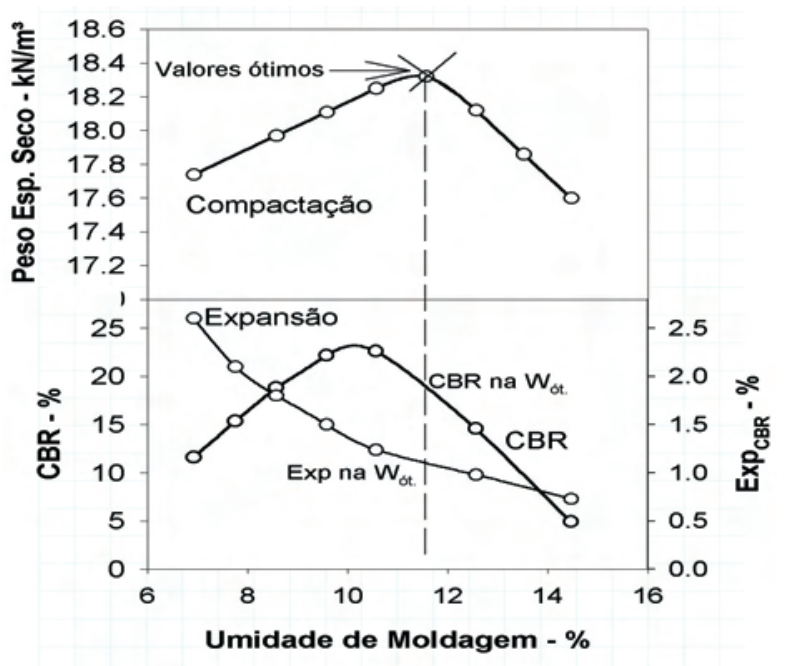

b) Solo 2

Figura 1 - Curvas de compactação, CBR e expansão ${ }_{\mathrm{CBR}}$ obtidas em ensaios $\mathrm{CBR}_{5 \text { pontos}}$, com compactação na energia do Proctor intermediário.

Figure 1 - Compaction, CBR and swelling ${ }_{C B R}$ curves obtained from $C B R_{5 \text { points }}$ tests performed at the Intermediate Proctor compaction effort.

R. Árvore, Viçosa-MG, v.30, n.4, p.619-627, 2006
Nota-se, também, que é possível obter valores dos parâmetros CBR e expansão ${ }_{\mathrm{CBR}}$ para variações do teor de umidade em torno de $\mathrm{W}_{\text {ot }}$, por exemplo $\pm 2 \%$, que são de importância fundamental para o controle da compactação a ser executado no campo, quando da execução de camadas estabilizadas do pavimento.

Na Figura 2, apresentam-se os valores dos parâmetros $\mathrm{W}_{\text {ót }}$ e $\gamma_{\text {dmáx }}$, das misturas solo-"grits", considerando as energias de compactação dos ensaios Proctor intermediário e Proctor modificado. Através desses dados, constatase que: (i) no solo 1 , houve tendência de queda $\mathrm{W}_{\mathrm{ot}}$, em razão de acréscimos nos teores de resíduo e aumento nos valores de $\gamma_{\text {dmáx }}$, em ambas as energias de compactação; e (ii) no que se refere ao solo 2 , observou-se um comportamento diferenciado, ou seja, aumento no $\mathrm{W}_{\text {ót }}$ e queda no $\gamma_{\text {dmáx }}$, devido ao acréscimo no teor de "grits", em ambas as energias de compactação. Como já esperado, em ambos os solos, o aumento da energia de compactação foi responsável por menores valores de $\mathrm{W}_{\text {ót }}$ e maiores valores de $\gamma_{\text {dmáx. }}$

\subsection{Avaliação do CBR e da expansão das misturas solo-"grits"}

Definidos os parâmetros ótimos de compactação, determinaram-se os valores dos parâmetros CBR e expansão das misturas solo-"grits". Na Figura 3, é possível observar a influência da adição de teores de "grits" aos solos 1 e 2, trabalhando-se na energia do ensaio Proctor intermediário. Em todas as misturas com o solo 1, observouse que ocorreram ganhos no CBR, sendo que, a partir do teor de "grits" de $8 \%$, as misturas apresentaram valores superiores a $20 \%$ desse índice, qualificando o solo1 para uso como camada de sub-base de pavimentos rodoviários flexíveis (DNIT, 1996), condição que não possuía quando compactado em sua forma natural. Destaca-se que a melhor resposta mecânica ocorreu no teor de "grits" de $28 \%$, notando-se um ganho de resistência mecânica da ordem de $127 \%$ em relação ao solo 1 , sem "grits".

No solo 2, também ocorreram ganhos de resistência mecânica em todos os tratamentos com "grits", observandose pequena variação nos valores CBR dos teores de "grits" entre 12 e $28 \%$; destaca-se que todos os teores de resíduo utilizados, à exceção de $4 \%$, produziram misturas que podem ser empregadas como camadas de sub-base de pavimentos rodoviários flexíveis (DNIT, 1996), sendo que o maior ganho ocorreu no porcentual de $28 \%$ de resíduos, atingindo-se um ganho de aproximadamente $190 \% \mathrm{em}$ relação ao solo 2 , em sua forma natural. 


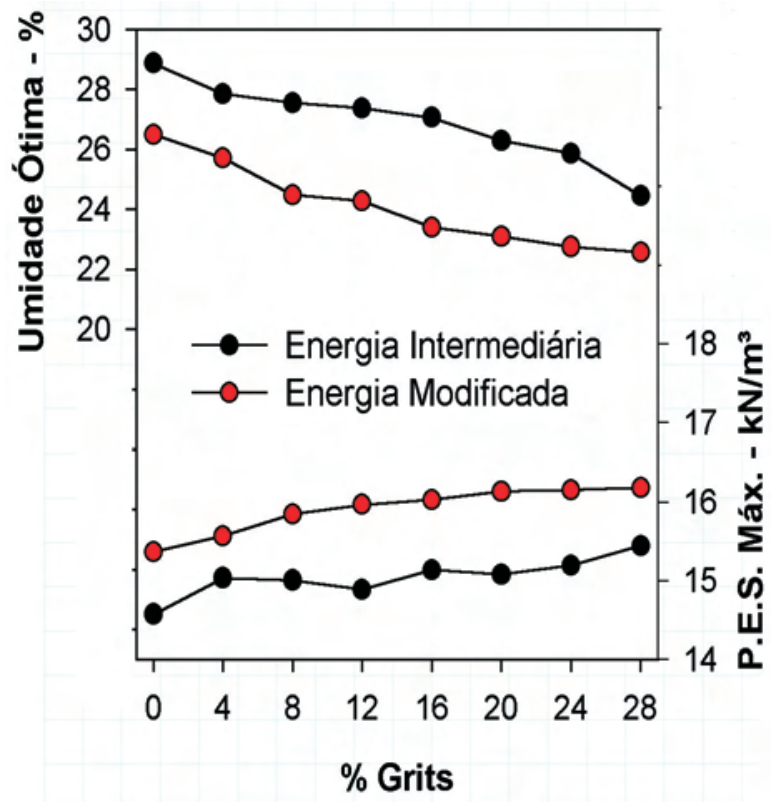

a) Solo 1

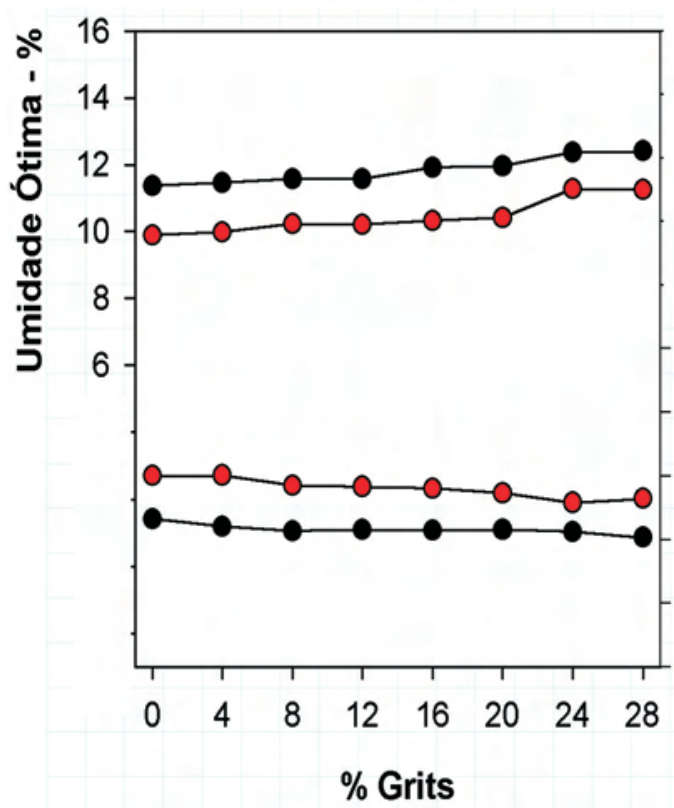

b) Solo 2

Figura 2 - Influência da adição de "grits" nos parâmetros ótimos de compactação dos solos 1 e 2 .

Figure 2 - Influence of grits addition on optimum compaction parameters of soils 1 and 2.

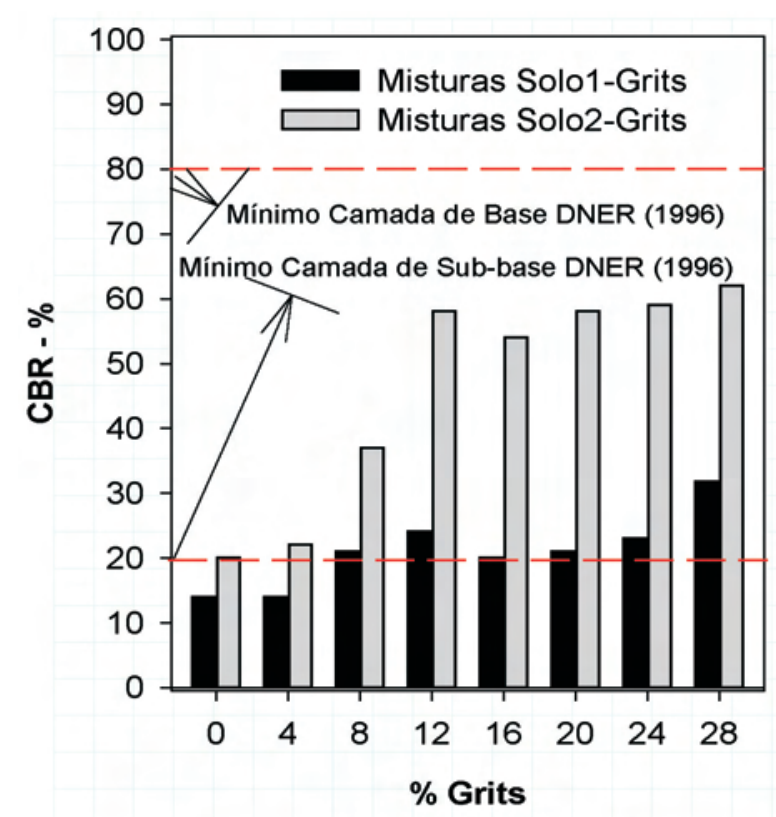

a) Índice CBR

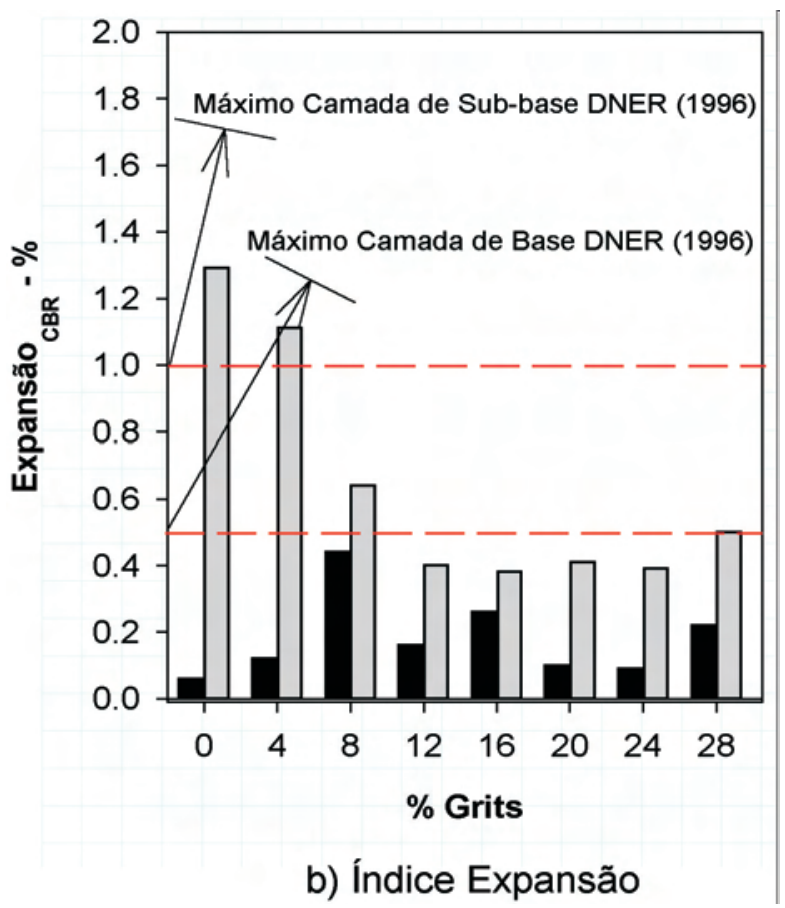

Figura 3 - Valores de CBR e expansão para as misturas solo"grits" referentes à energia do ensaio Proctor intermediário.

Figure 3 - CBR and swelling values from soil-grits mixtures at the Proctor intermediate compaction effort.

R. Árvore, Viçosa-MG, v.30, n.4, p.619-627, 2006 
Com relação à expansão, nas misturas com o solo 1 , ocorreram aumentos em todos os tratamentos com "grits", sendo esses considerados de pequena monta em se tratando de pavimentação rodoviária. A pequena oscilação dos valores pode ser associada ao fato de os extensômetros de medição serem muito sensíveis, e uma mínima mudança da posição do tripé de leitura pode levar à ocorrência de pequenas variações. Com relação às misturas solo 2-“grits", o parâmetro expansão teve o seguinte comportamento: (i) queda em todas as misturas com relação ao solo sem adição de resíduo; (ii) diminuição mais acentuada nos traços com 12, 16, 20 e $24 \%$ de "grits", em que, de $1,3 \%$ de valor de expansão no solo 2 , obteve-se o valor de $0,40 \%$; e (iii) pequeno aumento da expansão, apesar de ficar abaixo do valor do solo natural, no teor de $28 \%$ de "grits".

\subsection{Influência da umidade no CBR e expansão das misturas solo-"grits"}

A Figura 4 a ilustradas relações entre teor de umidade, CBR e expansão nas variações de $\pm 1 \%$ e $\pm 2 \%$ em torno da Wót. de moldagem dos corpos-de-prova, trabalhando-se na energia de compactação do ensaio Proctor intermediário. Nas misturas solo 1-"grits", observou-se a ocorrência de maiores valores dos parâmetros CBR e de expansão nos ramos secos das curvas de compactação, os quais continuam a cair nos ramos úmidos, como é comum no caso de solos. No caso das misturas solo 2-"grits", notou-se no parâmetro CBR a ocorrência de comportamento diferente daquele observado nas misturas com o solo 1 , verificando-se que, nos teores de "grits" entre 4 e $16 \%$, os maiores valores de CBR estão associados aos teores ótimos de umidade de cada mistura; quanto ao parâmetro expansão dessas misturas, notou-se, em geral, a ocorrência de maiores valores nos ramos secos das curvas de compactação, com quedas associadas ao crescimento nos teores de umidade de moldagem dos corpos-de-prova, à semelhança do que ocorreu com as misturas solo 1-“grits".

\subsection{Influência da energia de compactação na resistência e expansão das misturas solo-"grits"}

O efeito do aumento da energia de compactação no comportamento do parâmetro CBR pode ser analisado de duas maneiras: (i) ganho de resistência em função de um melhor arranjo de partículas e maior redução dos vazios dos solos; e (ii) perda de resistência em função da ocorrência de esmagamento de partículas, em razão do tipo de solo considerado. No que tange a esse item, as misturas solo-"grits" apresentaram o comportamento ilustrado na Figura 5, quando compactadas nas energias dos ensaios Proctor intermediário e modificado, podendo-se referir a: (i) queda nos valores do parâmetro CBR em todas as misturas solo 1-“grits", atingindo-se reduções médias de CBR de $24 \%$ e aumentos da expansão de teores de "grits" iguais ou superiores a $12 \%$, embora esses aumentos possam ser considerados de pequena monta para fins rodoviários; e (ii) ganhos de resistência, devido ao aumento da energia de compactação, nas misturas solo 2-"grits" a partir do teor de $20 \%$ de resíduo, que atingiram aproximadamente $20 \%$, no caso das misturas com 24 e $28 \%$ de "grits" e aumentos bruscos no parâmetro expansão, que chegaram a atingir a casa dos $500 \%$ nas misturas com 16 e $20 \%$ de resíduo; destaca-se que esses aumentos podem estar associados a um comportamento resiliente do solo 1, de textura areno-silto-argilosa, em conjugação com a energia de compactação elevada utilizada.
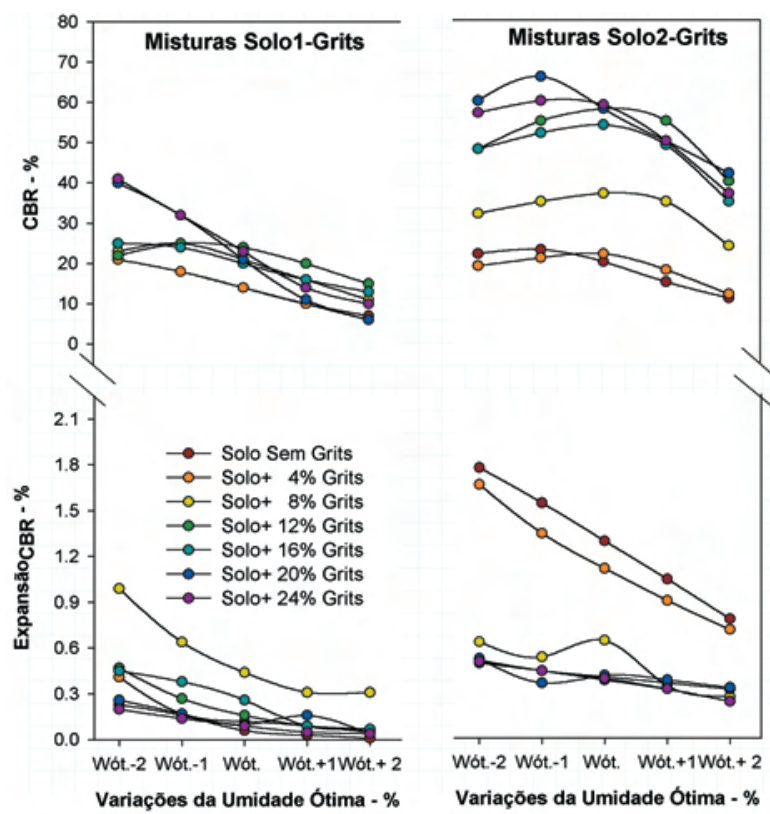

Figura 4-CBR e expansão das misturas solo-"grits", compactadas na energia intermediária, na $\mathrm{W}_{\text {ót }}$ e em variações $\mathrm{da} \mathrm{W}_{\mathrm{ot}} . \pm 1 \% \mathrm{e} \mathrm{W}_{\mathrm{ot}} . \pm 2 \%$.

Figure 4-CBR and swelling from soil-grits mixtures at the intermediate compaction effort, considering moisture content and variations of $\pm 1 \%$ and $\pm 2 \%$ around optimum moisture content. 


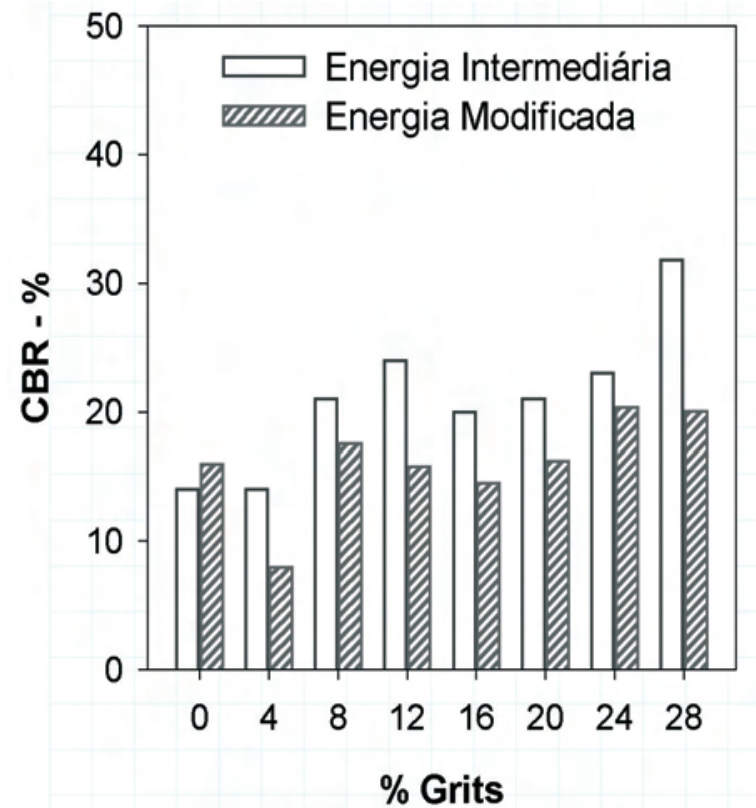

a) Misturas Solo1-Grits

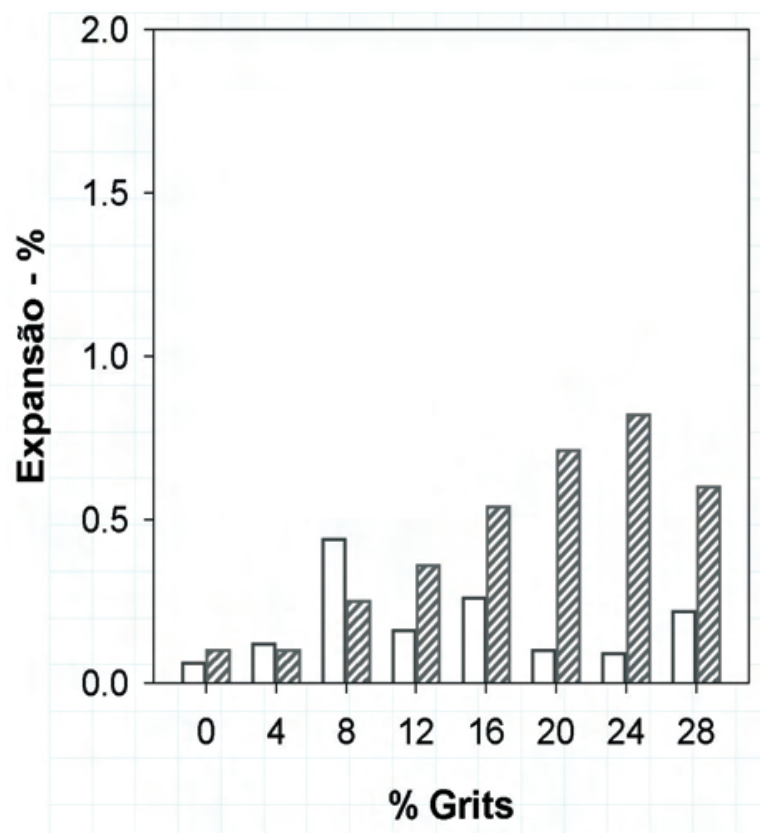

c) Misturas Solo1-Grits

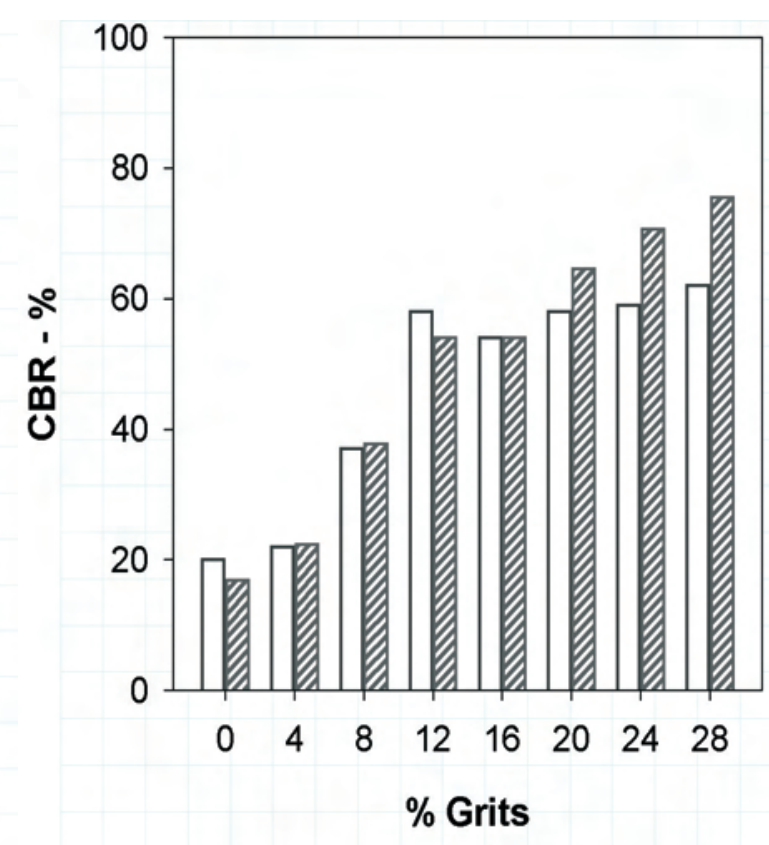

b) Misturas Solo2-Grits

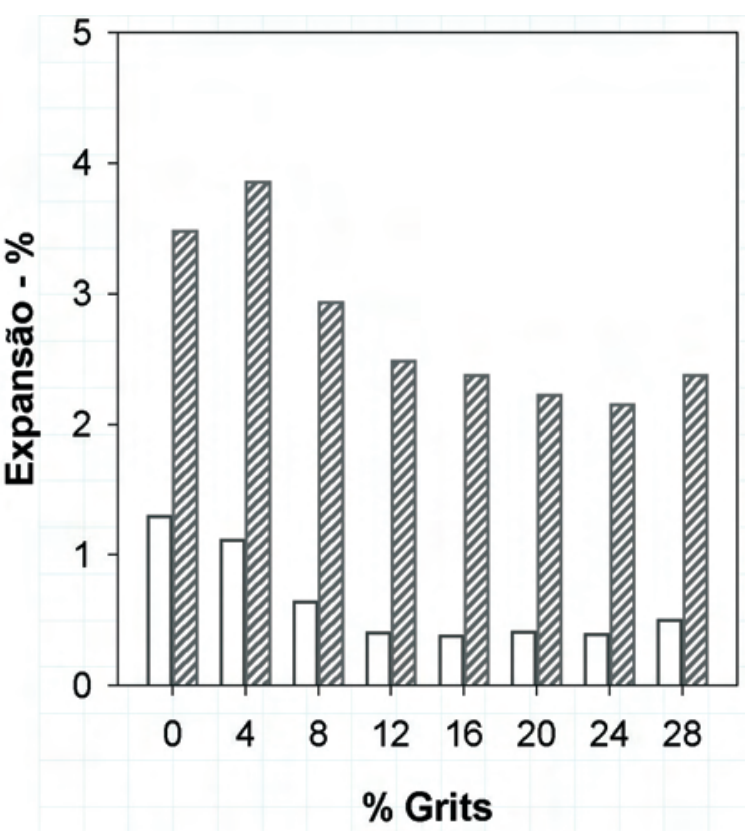

d) Misturas Solo2-Grits

Figura 5 - Influência da energia de compactação na resistência e expansão das misturas solo-"grits". Figure 5 - Influence of compaction effort on strength and swelling of soil-grits mixtures. 


\section{CONCLUSÕES}

(i) Considerando o parâmetro CBR como referência, os solos estudados se mostraram reativos ao "grits", obtendo-se melhor resposta para o solo 2, de textura arenosa. Em ambos os solos, as misturas com teores iguais ou superiores a $8 \%$ de "grits" apresentaram valores dos parâmetros CBR e expansão que as qualificam como camadas de sub-base de pavimentos rodoviários flexíveis, segundo os métodos de dimensionamento do DNIT.

(ii) As misturas de ambos os solos se mostraram sensíveis às variações de teor de umidade em torno de Wót., notando-se naquelas do solo 1 maiores valores de CBR nos ramos secos das curvas de compactação que diminuem com o aumento do teor de umidade e atingem os menores valores nos ramos úmidos das curvas de compactação; no entanto, as misturas com o solo 2 exibiram maiores valores $\mathrm{CBR}$, em geral, nos Wót.

(iii) Ambas as misturas não apresentaram, em geral, respostas mecânicas positivas ao aumento da energia de compactação, sendo que nas misturas com o solo 1 ocorreram quedas sucessivas no CBR, quando se trabalhou na energia do ensaio Proctor modificado. No que se refere às misturas com o solo 2 , foram observados ganhos da ordem de $20 \%$ no CBR, nos teores de 24 e $28 \%$ de "grits", que podem ser considerados de pequena monta, em especial quando se avaliam os custos envolvidos na execução de camadas de pavimentos rodoviários, ao se passar da energia do ensaio Proctor intermediário para o Proctor modificado. Assim, no presente caso, não se justifica empregar a energia de compactação do ensaio Proctor modificado na compactação das misturas no campo.

(iv) Na energia de compactação do ensaio Proctor intermediário, as misturas com o solo 1 apresentaram pequenos aumentos na expansão, observando-se comportamento inverso com as misturas com o solo 2 . No entanto, ao se aumentar a energia de compactação, passando a trabalhar com a energia do ensaio Proctor modificado, observou-se efeito deletério da energia no parâmetro expansão.

(v) O "grits" apresentou bom potencial para a estabilização das duas amostras de solo analisadas, visto que os resultados dessa etapa foram obtidos para corpos-de-prova não submetidos a períodos de cura. Em estudos de estabilização química de solos é comum trabalhar com períodos de cura da ordem de dias ou semanas, podendo-se referir a sete dias, no caso de misturas solo-cimento, e a 28 dias, em misturas solo-cal.

\section{RECOMENDAÇÃO}

Com base nos dados apresentados por ambos os solos e considerando os aspectos econômicos e técnicos, em que se ressalta o não-emprego de cura úmida dos corpos-de-prova, não se recomenda empregar a energia de compactação modificada para a execução das misturas solo-"grits" analisadas, nas situações deste trabalho.

\section{AGRADECIMENTOS}

Ao CNPq e à FAPEMIG, pelo apoio financeiro ao presente projeto, bem como à CAPES e à UFV, respectivamente, pela concessão da bolsa de doutorado e das instalações físicas para a execução deste trabalho. À empresa CENIBRA, pelo fornecimento do resíduo "grits".

\section{REFERÊNCIAS BIBLIOGRÁFICAS}

\section{ASSOCIAÇÃO BRASILEIRA DE NORMAS} TÉCNICAS - ABNT. NBR 10.004:

classificação de resíduos sólidos. Rio de Janeiro: 1987.6 p.

BALTAZAR, R. P. Caracterização do fator expansão de uma escória de aciaria em diferentes processos de cura para uso em pavimentação. 2001. $77 \mathrm{f}$. Dissertação (Mestrado em Geotecnia) Universidade Federal de Viçosa, Viçosa, 2001.

DEPARTAMENTO NACIONAL DE INFRAESTRUTURA DE TRANSPORTES - DNIT. ME

129: solos: compactação utilizando amostras não trabalhadas. Rio de Janeiro, 1994. 7 p.

\section{DEPARTAMENTO NACIONAL DE INFRA-} ESTRUTURA DE TRANSPORTES-DNIT. ME

216: solo-cimento: determinação da relação entre o teor de umidade e a massa específica aparente. Rio de Janeiro, RJ, 1994. 8 p. 
DEPARTAMENTO NACIONAL DE INFRAESTRUTURA DE TRANSPORTES - DNIT. Manual de pavimentação. 2. ed. Rio de Janeiro, 1996. 320 p. (Antigo DNER).

FERNANDES, D.C.M. Viabilidade do uso de alcatrão de madeira de eucalipto na estabilização de solos residuais para fins rodoviários. 2000. 124f. Tese (Doutorado em Ciências Florestais) - Universidade Federal de Viçosa, Viçosa, 2000.

FERRAZ, R.L. Contribuição ao estudo da estabilização de solos para fins rodoviários e habitacionais. 1994. $180 f$. Dissertação (Mestrado em Geotecnia) Universidade Federal de Viçosa, Viçosa, 1994.

LIMA, D.C.; MACHADO, C.C.; CARVALHO, C.A.B.; SILVA, C.H.C.; PEREIRA, R.S.; TRINDADE, T.P.; BARBOSA, P.S.A. A experiência da UFV no emprego de estabilizantes químicos em estradas florestais. In: SIMPÓSIO BRASILEIRO SOBRE COLHEITAE TRANSPORTE FLORESTAL, 6., 2003. Belo Horizonte. Anais... Belo Horizonte: SIF/UFV, 2003. p. 69-117.
LIMA, D.C.; BUENO, B.S.; SILVA, C.H.C.

Estabilização dos solos II: técnicas e aplicações a solos da microrregião de Viçosa. Viçosa, MG: Universidade Federal de Viçosa, 1993. 32 p. (Publicação, 333).

NOGAMI, J.S.; VILLIBOR, D.F. Pavimentação de baixo custo com solos lateríticos. São Paulo: Villibor, 1995. 240 p.

SANT'ANA, A.P. Caracterização

tecnológica de misturas solo-escória de alto forno moída para fins

rodoviários. 2003. 74f. Dissertação (Mestrado

em Geotecnia) - Universidade Federal de Viçosa, Viçosa, 2003.

SHERWOOD, P. T. Soil stabilization by the use of chemical admixtures. Roads and road constructions. S.L.: s. n., 1961. p. 102-119.

VIEIRA, S. V. Estabilização de solos com licor negro kraft concentrado para fins rodoviários. 1994. 126f. Dissertação (Mestrado em Ciências Florestais)-Universidade Federal de Viçosa, Viçosa, 1994. 